\title{
ELIZABETH DIECKERMANN
}

THE NEW ZEALAND DOCTOR'S ROLE IN CHILD SEXUAL ABUSE INTERVENTION: A LEGAL ANALYSIS

\section{LLB (Hons)}

\section{LAWS 513: LAW AND MEDICINE}

\section{FACULTY OF LAW}

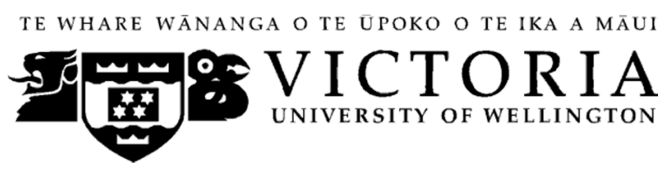

2013 


\section{Abstract}

This paper examines the New Zealand health professional's role (with an emphasis on doctors) in several aspects of child sexual abuse intervention and treatment. Both current and proposed legal provisions are considered. After an explanation of their important role in this area, the current child protection framework insofar as it is relevant to health professionals is outlined. This is followed by an analysis of changes proposed in the Government's White Paper for Vulnerable Children and Vulnerable Children Bill which will affect the landscape in which health professionals work. While there are benefits to proposed measures, some raise privacy and ethical concerns, or are inadequate to address the problem. The paper then addresses the legal requirements around the undertaking of medical examinations following a sexual abuse allegation, observing that the legislation raises questions around issues of consent, and making some suggestions for amendment. Finally, the general healthcare needs of adult survivors of abuse are considered.

Key words: child sexual abuse, health professionals, vulnerable children 


\section{Contents}

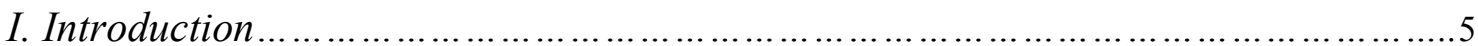

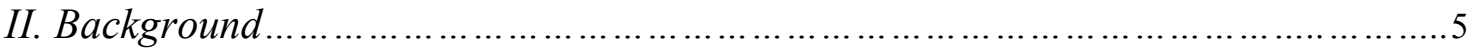

III. The Important Role of Health Professionals ......................................................6

IV. Prevention, Detection and Reporting: A Clash of Rights and Interests..............8

A. The Tension between Protection and Other Interests........................................

B. Child Protection and New Zealand Privacy Law ......................................... 8

V. Prevention: The Current Position................................................................11

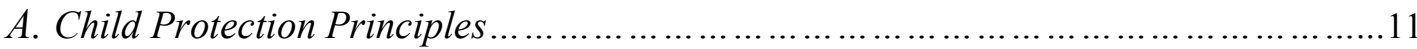

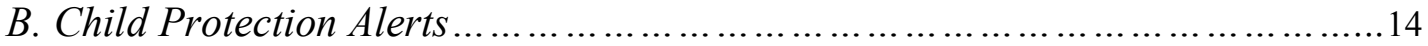

VI. Proposed Measures for the Identification of "Vulnerable Children"..................16

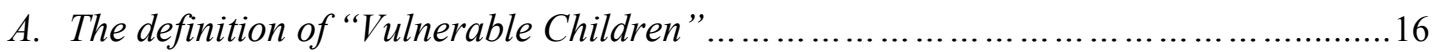

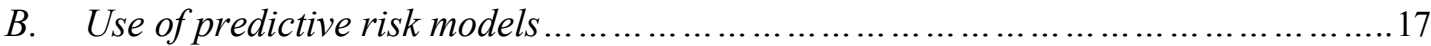

1. The proposed model ...................................................................... 17

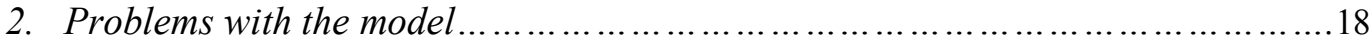

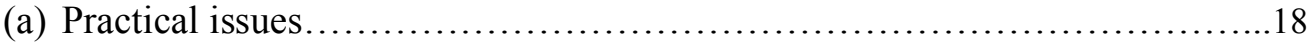

(b) Ethical and privacy concerns.............................................. 18

(c) Effectiveness of the model................................................20

3. Conclusions on the Predictive Risk Model ................................................21

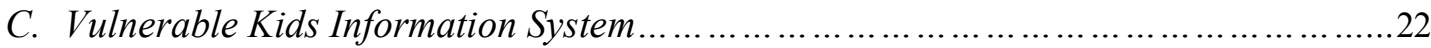

VII. Proposed Reporting Measures ......................................................24

A. Mandatory Child Protection Policies .........................................................24

1. The new legislative requirement, and its shortcomings................................24

2. An alternative: the development of a national child protection policy...............25

B. Training for Professionals Working with Children .........................................28

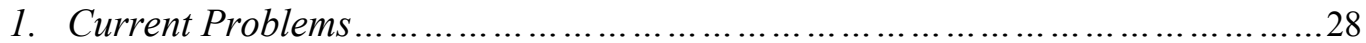

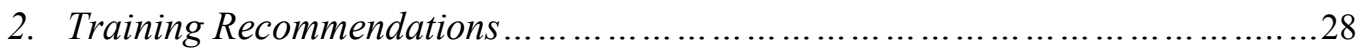

VIII. Medical Examinations Following Suspected Sexual Abuse ...............................29

A. The Purpose of Medical Examinations.........................................................29

B. The Effect of Medical Examinations on Abused Children ….................................30

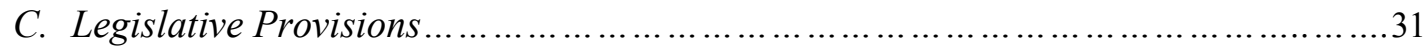


D. Child or Young Person's Consent or Refusal of Medical Examination..................33

1. Consent to general medical examinations ....................................... 33

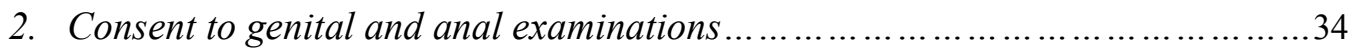

E. Requirements for Doctors Conducting Medical Examinations Following Sexual

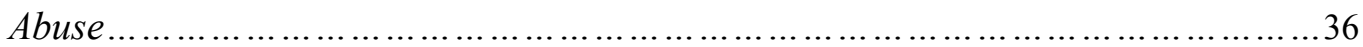

F. Recent Developments: Sexual Abuse Assessment and Treatment Services...............36

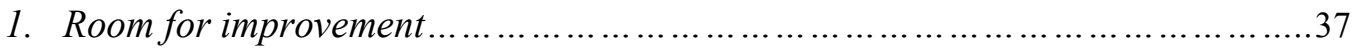

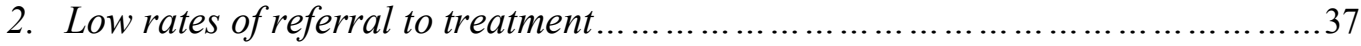

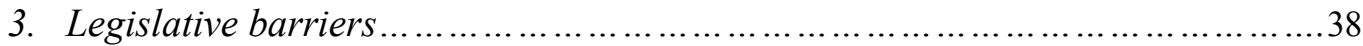

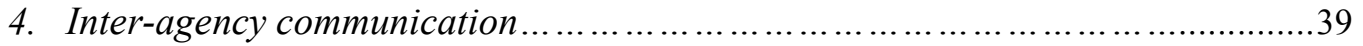

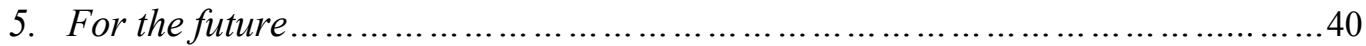

IX. Health Care for Adult Survivors of Child Sexual Abuse .................................41

A. The Enduring Effects of Child Sexual Abuse ........................................... 41

B. The Relevance of Child Sexual Abuse History to the Provision of Health Care .........42

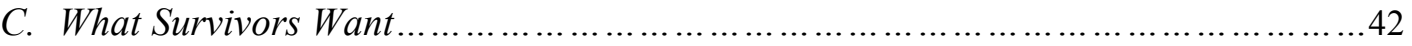

D. Survivor's Suggestions and Possible Alternatives .........................................43

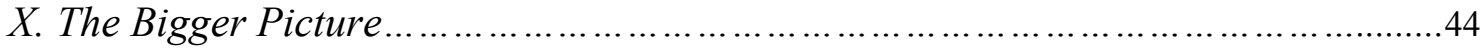

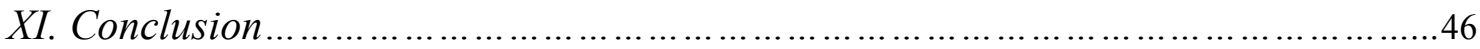

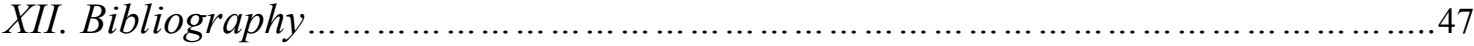




\section{Introduction}

This paper analyses the role of New Zealand health professionals in the prevention, detection, reporting and treatment of child sexual abuse. After providing some background and insight into New Zealand's child abuse problem this paper addresses prevention, detection and reporting measures that affect health professionals, with particular focus on proposals in the Government's White Paper for Vulnerable Children ${ }^{1}$ and Vulnerable Children Bill. ${ }^{2}$ It then focuses on current arrangements for medical examinations and treatment after a disclosure or suspicion or sexual abuse, with some recommendations for reform. The paper finishes with a brief consideration of the interests of adult survivors of child sexual abuse and how general healthcare can be provided in a manner that is sensitive to patients' potential trauma.

\section{Background}

Sexual violence is a grave social problem in Aotearoa New Zealand, with an estimated 29\% of women and $9 \%$ of men experiencing unwanted sexual contact over their lifetime. ${ }^{3}$ Even more alarmingly, children and adolescents make up the majority of sexual abuse victims although they comprise about only $20 \%$ of the population. ${ }^{4}$ New Zealand studies suggest that one in four girls will be subject to child sexual abuse, as well as a smaller but not insignificant proportion of boys. ${ }^{5}$ While there are many factors that contribute to rates of abuse within different geographical areas and social groups, children in rural areas and Maori are especially vulnerable. ${ }^{6}$

The short and long term physical and psychological effects of childhood sexual abuse have been well documented, often persisting into adulthood and affecting survivors for the rest of their lives. Particularly enduring are psychological sequelae including post-traumatic stress disorder (PTSD), depression, suicide attempts, anxiety and relationship or trust issues. Sexual

\footnotetext{
${ }^{1}$ Ministry of Social Development (2012) White Paper for Vulnerable Children, Wellington, New Zealand.

${ }^{2}$ Vulnerable Children Bill 2013 (150-1).

${ }^{3}$ P Mayhew and J Reilly (2009), Ministry of Justice, The New Zealand Crime and Safety Survey 2006.

${ }^{4}$ Judith Daylen, Wendy van Tongeren Harvey and Dennis O'Toole Trauma, Trials and Transformation: Guiding Sexual Assault Victims through the Legal System and Beyond (Irwin Law, Toronto, 2006) at 22.

5 Janet Fanslow, Elizabeth Robinson, Sue Crengle and Lana Perese "Prevalence of Child Sexual Abuse Reported by a Cross-sectional Sample of New Zealand Women”(2007) 31 Child Abuse and Neglect 935 at 936, and Rose Everitt, Peter Reed and Patrick Kelly "Medical Assessment for Child Sexual Abuse: A post-code lottery?"(2011) 48 Journal of Paediatrics and Child Health 389 at 389.

${ }^{6}$ Fanslow, Robinson, Crengle and Perese, above n 5 at 936.
} 
violence is also one of the most costly crimes, draining the New Zealand economy of an estimated $\$ 1.2$ billion each year. ${ }^{7}$ As well as the inherent value in intervening in cases of abuse and helping survivors to heal, appropriate intervention and treatment have the potential reduce the cost of sexual abuse to society by easing rates of reactive abuse, re-victimisation, mental and physical illness, substance abuse and crime among survivors.

The Government's White Paper for Vulnerable Children (White Paper) released in 2012 outlines proposed measures aimed at addressing New Zealand's appalling rate of child abuse. It was followed by the recently released Vulnerable Children Bill which makes some of the legislative changes proposed by the White Paper. Very little effort is made to address sexual abuse specifically. This may be due to the perception that sexual abuse is caused by "individual pathology, and aberrant sexual arousal and behaviour by the perpetrator" ${ }^{8}$ - an individual problem to be addressed by the criminal justice system. Although sexual abuse is less correlated with factors such as education, employment and poverty than other types of maltreatment, ${ }^{9}$ ignoring environmental and systemic factors which contribute to sexual abuse and aid its concealment put more children at risk. While high profile cases of physical abuse are often see as failures of the child protection system, coverage of sexual abuse largely focuses on perpetrators. Furthermore, disproportionate attention on predators within the children's workforce and "stranger danger" has spawned misconceptions and "hysteria",10 around abuse. Suspicion cast on more visible groups such as male teachers distracts from the fact that most child sexual abuse is committed by close relatives and family friends.

\section{The Important Role of Health Professionals}

Health professionals have an important role to play in every aspect of preventing and treating child sexual abuse. In relation to prevention, this paper focuses in particular on "frontline" professionals providing primary health care, such a general practitioners and public health nurses. The Government's White Paper places emphasis on the position of such professionals as they have day-to-day contact with children and are in a position to detect signs of abuse,

\footnotetext{
${ }^{7}$ T Roper and A Thompson (2006), Estimating the costs of crime in New Zealand in 2003/04, New Zealand Treasury Working Paper 06/04.

${ }^{8}$ Ministry of Social Development (2012) “White Paper for Vulnerable Children” Volume II Wellington, New Zealand at 32.

${ }^{9}$ Ministry of Social Development above $\mathrm{n} 8$ at 32

10 “Child Abuse Hysteria” Sunday Star Times (New Zealand 8 September 2013) at 1.
} 
both through their medical understanding of types of injury and their probable cause, and through specific training on injuries or behaviour indicative of abuse. It is vital that professionals who work in universal services are equipped to identify children who are experiencing or vulnerable to abuse in order to refer them to more specialised services. This is all the more important in the context of sexual abuse because it is less closely correlated with traditional "risk factors" than other types of abuse, thus making children who are vulnerable more difficult to identify through risk modelling or other statistics-based systems. ${ }^{11}$ Doctors also ideally provide an unbiased outsider perspective where sexual abuse is being overlooked because family/whanau or community members are preoccupied or abuse is entrenched and intergenerational.

Doctors and nurses are also involved with the medical examinations, treatment and follow-up that are necessary after a disclosure of sexual abuse. They are therefore in a position to observe the physical and psychological effects of sexual abuse on children and influence recovery through the way they conduct examinations and treatment. There is some evidence that the medical examination has the potential to retraumatise a child, but conversely, if conducted in the right manner may aid the child in taking back control over his or her own body. ${ }^{12}$ The forensic examination carries with it a potential for conflict between the interests of justice and the wishes of the child, which the doctor must navigate carefully to balance the public interest in convicting the perpetrator with the need not to undermine the child's recovery. When these weighty issues are considered, it becomes clear that doctors' and nurses' expertise must go beyond the technicalities of the medical examination.

These considerations highlight the importance of the role of health professionals in addressing New Zealand's child sexual abuse problem. Doctors and nurses as a group have the potential to make a significant difference in improving the prevention and treatment of child sexual abuse if the legal structure in which they work allows them to do so. This paper addresses the relevant policies and related legal provisions which influence health professionals' ability to identify and address the needs of vulnerable children, abused children and survivors.

\footnotetext{
${ }^{11}$ Ministry of Social Development above n 8 at 32.

${ }^{12}$ Helen Britton "Emotional Impact of The Medical Examination for Chid Sexual Abuse" (1998) 22 Child Abuse and Neglect 573 at 573.
} 


\section{Prevention, Detection and Reporting: A Clash of Rights and Interests}

\section{A. The Tension between Protection and Other Interests}

Although separate matters, prevention, detection and reporting overlap. One issue that they share is a tension between an individual's interest in privacy and minimal interference and society's interest in protecting children by intervening at the earliest opportunity to prevent or recognise and address abuse. Many of the proposed measures such as predictive risk modelling, mandatory reporting, information sharing systems and early intervention carry with them this inherent conflict. Any policy must balance these competing considerations, bearing in mind that inappropriate intervention may also have adverse effects on children. ${ }^{13}$

Another concern is the grave nature of a child abuse allegation, the danger of undermining the presumption of innocence and the effect of a false allegation on the accused. As the White Paper notes, "it is hard to exaggerate the extent of the rage, humiliation and fear felt by parents or other adults who are subject to child protection investigations where the concerns are not substantiated". ${ }^{14}$ Intended measures outlined in the Government's White Paper, such as the use of abuse prediction tools, information sharing and the controversial proposal for new "child harm prevention orders" in the civil jurisdiction (which will be possible when is abuse is proved on the balance of probabilities) indicate that the current government is willing to partially sacrifice these rights and concerns in the interests of child protection.

\section{B. Child Protection and New Zealand Privacy Law}

Failure of the child protection system to identify and prevent serious abuse is often attributed, at least in part, to the reluctance or inability of agencies to share information. In the case of the serious abuse of nine year old girl "M", many different agencies were involved with M and her family, none of which adequately communicated with other agencies to voice concerns. ${ }^{15}$ In his report on the case Mel Smith called for changes to the legislative framework in order to facilitate sharing of information whenever it is necessary to protect

\footnotetext{
${ }^{13}$ Ministry of Social Development above n 1 at 63 .

${ }^{14}$ Ministry of Social Development above n 1 at 63.

${ }^{15}$ Mel Smith "Report to Hon Paula Bennett, Minister of Social Development Following an Inquiry into the Serious Abuse of a Nine Year Girl, and Other Matters Relating to the Welfare, Safety and Protection of Children in New Zealand, 31 March 2011 at 28.
} 
children and give clarity to frontline professionals as to the circumstances in which they can lawfully disclose personal information. ${ }^{16}$ The Law Commission's recent review of the Privacy Act 1993 also highlighted the uncertainty around privacy law, resulting in disagreement between agencies as to what constitutes lawful sharing. ${ }^{17}$

The sharing of information between agencies may contribute to the efficient provision of services, the detection of wrongdoing, or a better understanding of our society through research and statistics. As observed by the Law Commission, the prevention of child abuse is a clear example of an effort in which a coordinated response is invaluable. ${ }^{18}$ The physical ability to share information has increased dramatically in a very short space of time, with the rise of technology which enables incredibly easy storage, access and disclosure of vast amounts of information. While this technology has the potential to improve child protection, it also comes with dangers, including the leaking, oversharing or misuse of sensitive information. ${ }^{19}$

In response to the concerns about the ambiguity of privacy law and the need to make provision for to changes in technology, the Law Commission made several recommendations for Privacy law reform, some of which were implemented by the Privacy Amendment Act $2013 .^{20}$ Most significant for child protection is the introduction of Approved Information Sharing Agreements (AISAs). ${ }^{21}$ This reform allows state and private sector agencies to formulate agreements to share specified information for particular purposes, including sharing that may be outside the principles of the Privacy Act. These agreements must specify the type of information to be shared, the purpose for sharing and the safeguards that will be put in place to protect individuals' privacy. ${ }^{22}$ They are subject to substantial approval and review processes and must be publically and freely available on agencies' websites and in schedule $2 \mathrm{~A}$ of the Act. ${ }^{23}$

\footnotetext{
${ }^{16}$ Smith above $\mathrm{n} 15$ at 71.

${ }^{17}$ Law Commission Review of the Privacy Act (NZLC R123, 2011) at 326.

${ }^{18}$ Law Commission above $\mathrm{n} 17$ at 326.

${ }^{19}$ Law Commission above $\mathrm{n} 17$ at 325.

${ }^{20}$ Privacy Amendment Act 2013.

${ }^{21}$ Privacy Act 1993, pt 9A.

${ }^{22}$ Privacy Act 1993, s 96I.

${ }^{23}$ Privacy Act 1993.
} 
Prior to this amendment information sharing was not directly addressed in the Act, meaning that sharing was only legal if it was explicitly provided for in another Act, came within an exception to the privacy principles or was authorised by a Code of Practice issued by the Privacy Commissioner under s $46 .{ }^{24}$ Information sharing goes against the major principles in the Privacy Act, most notably that personal information should be collected directly from the individual, ${ }^{25}$ information collected for one purpose should not be used for another, ${ }^{26}$ and once collected it should not be disclosed to another person or agency. ${ }^{27}$ During the transition period in which AISAs are being developed, health professionals continue to operate under the old system, relying largely on the Health Information Privacy Code ${ }^{28}$ for authority on the acceptable use and sharing of health information. The Code largely reflects the Act's general privacy principles, except for some provisions addressing specific health matters such as the disclosure of general information (such as condition and location) to visitors of a patient in hospital, or informing family members of a death. ${ }^{29}$ For health professionals concerned with the safety of a patient, disclosure requires meeting the same the high threshold as enshrined in the Privacy Act. This means an agency must believe on reasonable grounds that disclosure is necessary to prevent or lessen a serious threat to the life or health of an individual (this was amended from "serious and imminent threat" this year). ${ }^{30}$ Furthermore, under the Code disclosure must be to an individual or agency with the "power to act urgently to achieve a tangible result in the particular case". 31

The development and approval of AISAs under the amendment may make the sharing of health information in the interests of child protection easier by lowering thresholds to be met before information can be disclosed to other agencies or allowing disclosure to agencies which do not have protection powers (such as other health services). Certainly, some of the White Paper's proposals for the identification of at-risk children will require a much more flexible approach to information sharing. Currently only one AISA has been approved, ${ }^{32}$ so it remains to be seen how much divergence from the principles of the Act will be permitted in

\footnotetext{
${ }^{24}$ Law Commission above $\mathrm{n} 17$ at 322.

${ }^{25}$ Privacy Act 1993, principle 2.

${ }^{26}$ Privacy Act 1993, principle 10.

27 Privacy Act 1993, principle 11.

${ }^{28}$ Privacy Commissioner "Health Information and Privacy Code 1994" (Incorporating Amendments) December 2008.

${ }^{29}$ Privacy Commissioner above n 28 at 64 .

${ }^{30}$ Privacy Commissioner above n 28 at 64 and Privacy Act s 6.

${ }^{31}$ Privacy Commissioner above n 28 at 65 .

${ }^{32}$ Information Sharing Agreement Between Inland Revenue and Internal Affairs (2013).
} 
the disclosure of health information under new agreements. The themes and proposals in the White Paper suggest that in the realm of child protection, privacy considerations will become secondary.

\section{Prevention: The Current Position}

During 2011 and 2012 three fifths of notifications to CYF resulted in no further action. ${ }^{33}$ This suggests that there are many families who are in a position to benefit from extra health or social services, but do not warrant CYF intervention. ${ }^{34}$ The law needs to support the early identification and guidance of families that need extra support rather remaining inactive until serious problems arise. Professionals coming into contact with children could also benefit from better understanding of risk factors and signs associated with sexual abuse and more information on the child's history. As explained above, professionals' disagreement over what constitutes lawful sharing has also hindered prevention and detection of abuse.

\section{A. Child Protection Principles}

The Children, Young Persons, and Their Families Act 1989 (CYPF Act) is the main legislation governing the protection of children identified as suffering or at risk of abuse. The Act is non-interventionist, focusing on the rights and responsibilities of families/whanau to make decisions about children's upbringing and ensure their safety. ${ }^{35}$ Its 1989 enactment introduced the Family Group Conference as a mechanism by which to empower families, whanau, hapu and iwi to participate in child protection by making plans to protect vulnerable children in their care. The title and object of the Act both reflect this emphasis by linking the wellbeing of children and young people to that of their families. ${ }^{36}$

\footnotetext{
${ }^{33}$ Ministry of Social Development above n 8 at 70

${ }^{34}$ Ministry of Social Development above $n 8$ at 70

${ }^{35}$ Pauline Tapp and Nicola Taylor "Protecting the Family" in Mark Henaghan and Bill Atkin (eds) Family Law Policy in New Zealand (Lexis Nexis, Wellington, 2007) 81 at 87.

${ }^{36}$ See Children, Young Persons, and Their Families Act 1989, s 4.
} 
The "paramountcy principle" is stated in s 6:

\section{"6 Welfare and interests of child or young person paramount}

In all matters relating to the administration or application of this Act...the welfare and interests of the child or young person shall be the first and paramount consideration, having regard to the principles set out in sections 5 and 13."

Sections 5 and 13 provide additional principles to guide those exercising powers under the Act. They strongly emphasise the family as primarily responsible for children and encourage the idea that children's best interests are served by growing up within their family and culture. The introduction of this approach may have been in response to the Maori "renaissance" and a desire not to undermine cultures that are highly family focused with damaging state intervention. ${ }^{37}$

Unfortunately, the emphasis on family involvement and empowerment has resulted in professionals focusing on adults rather than children in their decisions and assessments. ${ }^{38}$ The paramountcy principle in s 6 is left to the side, or interpreted in a way that assumes a child's best interests are always served by remaining with family. In $R e T A$ the judge expressed deep concern at the social worker's fixation on family autonomy and inability to follow the advice of medical professionals. ${ }^{39}$ Similarly Mel Smith's report on the abuse of M identified a key aspect of the failure of professionals to protect $\mathrm{M}$ as their disproportionate focus on helping M's mother with M's difficult behaviour rather than questioning its underlying causes. ${ }^{40}$

These cases demonstrate that the framework set up by the Act is encouraging a presumption of non-intervention and the prioritisation of family autonomy over child welfare. The Government has acknowledged the need to bring professionals back to a "child-centred approach" ${ }^{\natural 1}$ and responded by incorporating changes to the principles of the CYPF Act into the Vulnerable Children Bill. An additional principle is added to CYPF Act s 5: ${ }^{42}$

\footnotetext{
${ }^{37}$ Tapp and Taylor above $\mathrm{n} 35$ at 87.

${ }^{38}$ Smith above $\mathrm{n} 15$.

${ }^{39}$ Re TA [1997] NZFLR 885 as cited in Brookers Online "Care and Portection of Children".

${ }^{40}$ Smith above $\mathrm{n} 15$.

${ }^{41}$ Ministry of Social Development above $\mathrm{n} 8$ at 143.

${ }^{42}$ Vulnerable Children Bill 2013 (150-1), cl 102.
} 
"(g) the principle that decisions affecting a child or young person should be made by adopting a holistic approach that takes into consideration, without limitation, the child's or young person's age, identity, cultural connections, education, and health."

Section 13 is amended in two ways. A sub-section is added restating the section 6 principle that the child's welfare and best interests are the first and paramount consideration. ${ }^{43}$ The first part of the section, which requires consideration of s13 principles subject to sections 5 and 6 is replaced by: ${ }^{44}$

"In determining the welfare and interests of a child or young person, the court or person must be guided by the principle that children and young people need to be protected from harm and have their rights upheld, and also the principles in section 5 as well as the following principles"

These amendments basically re-arrange the words in the Act, but do not change the Act's focus. While they make the "principles hierarchy" more explicit and appear to elevate the consideration of protection from harm in a best interests analysis, they are unlikely to change the application of the Act in practice unless accompanied by training and child protection policies that emphasise the paramountcy principle and the importance of a child-centred approach. More effective would be amendment of the principles away from the minimal intervention approach. As Mel Smith observed, no research seems to have been done on how the ss 5,6 and 13 principles are being applied in practice. ${ }^{45}$ While the importance of family and culture are undeniable, it does not follow that a family empowerment mechanism is always appropriate. In families where abuse is engrained and intergenerational or it is accompanied by violence between adults, a family group conference may result in dominant and abusive members of the family forcing their views. ${ }^{46}$ In such a family, the placement of children with relatives in the interests of maintaining culture and family ties may result in the child being re-abused because similar problems exist within the extended family/whanau. This was what happened in the case of "M".

A re-thinking of the CYPF Act 1989 is needed in order to achieve a truly "child-centred" approach. In the meantime, the paramountcy of child welfare should be emphasised in

\footnotetext{
${ }^{43}$ Vulnerable Children Bill (150-1) cl 103(1).

${ }^{44}$ Vulnerable Children Bill (150-1) cl 103(2).

${ }^{45}$ Smith above $\mathrm{n} 15$ at 82.

${ }^{46}$ Brookers Online, above n 39.
} 
training and child protection policies to prevent professionals taking a "family preservation at all costs" approach.

\section{B. Child Protection Alerts}

The national child protection alert system, in place since 2009, is designed to draw health professionals' attention to existing information in records which may indicate vulnerability to abuse. ${ }^{47}$ "Alerts" are placed on the health files of at-risk children and pregnant women whose unborn children are judged to be vulnerable under the applied criteria. While alert systems have been used in individual DHBs for some years, expansion onto a national scale means alerts are now placed on the National Medical Warning System, allowing health professionals to see information on at-risk children even when they move between DHBs. ${ }^{48}$

For an alert to be placed two criteria must be satisfied. Firstly, a report of concern (ROC) must be made by a member of the DHB to CYF in respect of the child. Secondly, the placement of the alert must be approved by a multi-disciplinary team which considers that the ROC indicates the child may still be at risk. ${ }^{49}$ Once a ROC has been made it is highly likely that an alert will be placed, unless the ROC relates to a "stranger assault" or other isolated incident which is unlikely to affect the child's future risk of abuse. ${ }^{50}$

The system is based on the principle that a practitioner will make the best assessment when all relevant information is available. It also aims to address the under-diagnosis of abuse resulting from a "lack of diagnostic suspicion" by putting the possibility of abuse in the practitioner's mind during assessment. ${ }^{51}$ However, critics of the system have expressed concern that alerts will stigmatise parents of flagged children and encourage doctors to treat them like criminals. ${ }^{52}$ The danger of overreliance on the system also risks letting children without alerts fall through the cracks through the assumption that they are not at risk of abuse.

\footnotetext{
${ }^{47}$ Paediatric Society New Zealand Child Protection Special Interest Group Newsletter (September 2012) $<$ www.paediatrics.org $>$ at 1 .

${ }^{48}$ Auckland District Health Board, Board Policy Manual Section 5: Child Protection Alerts Management (December 2009) at 4.

${ }^{49}$ Paediatric Society New Zealand above n 47 at 1.

${ }^{50}$ Auckland District Health Board, above n 48 at 2.

${ }^{51}$ Auckland District Health Board above n 48 at 4.

52 Tony Wall “"'Critics warn on pregnant mother alerts” Sunday Star Times (New Zealand, 12 December 2010).
} 
These concerns highlight the importance of guidelines and appropriate training to accompany an alert system. The Auckland DHB has implemented a robust system to back the use of alerts, such as training on how to make high quality ROCs, immediate referral to the multidisciplinary team and rules emphasising that alerts are only an adjunct to clinical decisionmaking and do not mean that any new injury is non-accidental. ${ }^{53}$ A positive outcome of the system is the improvement in the quality of ROCs made to CYFs by the DHB since they have also been used internally. The alert system was developed by the current Children's Commissioner in conjunction with other child abuse experts and has been well received by health professionals. This speaks to the value of paediatricians and other professionals develop systems they will be working with.

While the benefits of the alert system are compelling, it is lacking a clear legal basis. It is not mentioned in current legislation, or in the Vulnerable Children Bill, and the lawfulness under the Privacy Act of sharing ROCs is dubious. ROCs trigger CYF's obligation to investigate the matters contained in the report, ${ }^{54}$ and determine whether the child is "in need of care and protection". 55 The need for care and protection must usually be established before any intervention, such as convening a Family Group Conference, can be carried out. By recording and sharing the fact that an ROC has been made, the child protection alert system is effectively by-passing the requirement that reports must be properly investigated before they are acted upon. There is a danger that alerts will remain in place even if reports are not substantiated and continue to haunt parents because they are carried over to subsequent children's files. Furthermore, it is uncertain whether the alerts conform to privacy law, given that no AISAs yet operate between DHBs. Child protection alerts violate both the principle against using information for another purpose, ${ }^{56}$ and the principle against disclosure. ${ }^{57}$ Even if it could be established that ROCs reflect a "serious threat", thus meet the threshold for noncompliance with the privacy principles, the requirement that disclosure be to a person with the power to respond to the threat is still not met as disclosure is between DHBs. The danger that the alert may remain in place despite the fact that the family's circumstances have

\footnotetext{
${ }^{53}$ Paediatric Society of New Zealand above n 47 at 1.

${ }^{54}$ Children, Young Persons, and Their Families Act 1989, s 17.

${ }^{55}$ As defined in Children, Young Persons, and Their Families Act, s 14.

${ }^{56}$ Privacy Act 1993 s 6, principle 10.

${ }^{57}$ Privacy Act 1993 s 6, principle 11.
} 
changed or the ROC was not substantiated also violates the principle that information must not be used without taking reasonable steps to ensure it is up to date and relevant. ${ }^{58}$

While child protection alerts enable health professionals to make assessments with more information on a child's history, there is no legal basis for this system. However, the development of an AISA between DHBs may provide the basis for the lawful sharing of this information. The reform gives health practitioners the opportunity to voice concerns that privacy law is to restrictive for the purposes of child protection, and obtain clear cut exceptions to the principles for the purposes of identifying at risk children and being informed as possible about a child's history when assessing an injury. Clearly, the system must be accompanied nation-wide by appropriate guidelines and training to ensure doctors do not make assumptions based on alerts alone, or stigmatise parents. As mentioned, this is already happening in the Auckland DHB that has had its own alert system for some years. However, often quality of services is not consistent across DHBs, with rural communities ultimately suffering most from gaps in training or resources. It is important that both the legal and practical concerns with this system are addressed.

\section{Proposed Measures for the Identification of "Vulnerable Children"}

\section{A. The definition of "Vulnerable Children"}

The Government's White Paper states an intention to enable professionals to identify "vulnerable children" and act earlier. Vulnerable children are defined in the paper as children who are at a "significant risk of harm to their wellbeing now and in the future as a consequence of the environment in which they are being raised". ${ }^{59}$ However, this definition seems to have been discarded in the drafting of the Vulnerable Children Bill: ${ }^{60}$

\section{"5(1) Interpretation}

vulnerable children means children of the kind or kinds (that may be or, as the case requires, have been and are currently) identified as vulnerable in the setting of Government priorities under section 7"

\footnotetext{
${ }^{58}$ Privacy Act 1993 s 6, principle 8.

${ }^{59}$ Ministry of Social Development above n 1 at 6.

${ }^{60}$ Clause 5 .
} 
Clause 7 throws little light on the matter; it simply stating that the "responsible minister" (to be appointed by the Prime Minister) "may" set Government priorities for improving the wellbeing of vulnerable children. ${ }^{61}$ The setting of priorities appears to be an option rather than a requirement, with no apparent time limit. Until priorities are set, the Government's conception of vulnerability remains unclear. However, the tone of the Bill and comments during the first reading suggest that the current Government sees "vulnerability" as meaning "at risk of abuse", rather than the wider conception of being disadvantaged by poverty and inequality. Proceeding on this assumption this section addresses issues around identifying "vulnerable" children and intervening before abuse actually occurs.

\section{B. Use of Predictive Risk Models}

\section{The proposed model}

The White Paper advocates the wide use of a predictive risk model (PRM) developed by the University of Auckland and tested by the Ministry of Social Development. It is claimed that vulnerability to abuse can be identified through the use of statistical criteria, so risk can be assessed simply by entering certain information about a child and their family circumstances. ${ }^{62}$ The proposed model uses 132 different variables to calculate a risk decile for an individual child - most variables relating to demographics, benefit history, care and protection history and parental history and characteristics. ${ }^{63}$ The model has been found to be reasonably effective in predicting the risk of substantiated maltreatment in the population it assesses, with children placed by the model in the highest risk decile being 25 times more likely to have a substantiated case of maltreatment by the age of five than children in the lowest. ${ }^{64}$ However, the model is only designed to assess children who come into contact with the benefit system before they reach two years of age - a very small percentage of the population.

The Government has characterised this model as a better and more efficient use of information that is already held by various agencies, enabling resources to be targeted to

\footnotetext{
${ }^{61}$ Clause 7.

${ }^{62}$ Ministry of Social Development above $\mathrm{n} 1$ at 10.

${ }^{63}$ Rhema Vaithianathan, Tim Maloney, Emily Putam-Hornstein, Nan Jiang "Children in the Public Benefit System at Risk of Maltreatment: Identification via Predictive Modelling” (2012) 45 American Journal of Preventative Medicine 354 at 355.

${ }^{64}$ Vaithianathan above $\mathrm{n} 63$ at 357.
} 
children who are more at risk. ${ }^{65}$ It is unclear from the White Paper whether the Government intends CYF to control the use of the model and convey risk assessments to health professionals, or whether clinicians will be using the tool directly to aid their assessments, as the developers seem to suggest. ${ }^{66}$

\section{Problems with the model}

(a) Practical issues

The Government and developers of the PRM have claimed the model is a simple, accurate and cost effective way of predicting risk of abuse. ${ }^{67}$ According to the White Paper, the system will take information "buried in databases" and use it to identify up to 30000 at-risk children, enabling social workers and doctors to "take a closer look" ${ }^{68}$ However, the White Paper does not address how administrative data is to be gathered from various departments every time a young child enters the benefit system (thus qualifying for assessment under the model). Collecting and entering data for 132 variables, including obscure information relating to the histories of caregivers, partners and siblings is a huge task. The Vulnerable Children Bill makes no mention of the PRM so remains unclear how it will be implemented and what legal status it will have. Currently CYF can require information to be supplied by Government departments through section 66 of the CYPF Act 1989, but this process is too inefficient to gather the vast amount of information required to use the model. Even the use of AISAs may be cumbersome. If the PRM is to be used by health professionals, the developers of the tool have warned that expensive clinical training will be necessary to ensure it is applied properly. ${ }^{69}$

(b) Ethical and privacy issues

One of the biggest limitations of the PRM is the ethical concerns it raises. While PRMs are used widely in the healthcare setting to predict risk of various illnesses, ${ }^{70}$ this attempt to apply it to child protection basically proposes using statistics to predict the likelihood of

\footnotetext{
${ }^{65}$ Ministry of Social Development, above n 1 at 10.

${ }^{66}$ Vaithianathan above $\mathrm{n} 63$ at 358

${ }^{67}$ Vaithianathan above $\mathrm{n} 63$ at 354

${ }^{68}$ Ministry of Social Development above $\mathrm{n} 1$ at 11.

${ }^{69}$ Vaithianathan above $\mathrm{n} 63$ at 357

${ }^{70}$ Vaithianathan above n 63 at 358
} 
individual criminal behaviour. While a caregiver's history of abusing or allowing abuse is a relevant factor in predicting their ability to care for children in the future, the model's use of data such as family status, employment or a parent's own history as an abuse victim is extremely problematic. It serves to stigmatise certain families and blurs the line between causation and correlation, causing individuals to come under suspicion because of characteristics or circumstances outside their control. The fact that the model is applicable only to children in the benefit system is discriminatory and compounds the stigma and hostility that beneficiaries already experience.

The compilation of information from different sources is also a breach of children's and caregivers' privacy under the privacy principles even if each piece of information is already held by the state. The model will be applied to assess children's level of risk without the consent of those involved and information will be applied by a different agency and for a different purpose than initially intended. Presumably, AISAs between CYFs and other agencies will be developed to give legal authority to this type of collection and use of personal information. This will require serious incursions into the principles of privacy given that the model proposes the use of information to assess risk. This is far from meeting the Privacy Act's requirement that a serious threat is already established on reasonable grounds before information can be disclosure or used for a different purpose. The Health Privacy Code requires non-compliance with privacy principles to be proportionate to the threat perceived. ${ }^{71}$ It is highly doubtful that the use of personal information in the way the model proposes can be seen as proportionate, when a threat is not yet even established. To mitigate this disregard for privacy principles, access to information entered in the PRM must be strictly limited (for example the head social worker using the tool), and restrict others such as schools and health professionals to knowledge of the child's resulting risk decile.

Lastly, it is unclear what level of action is appropriate once a child is classified as being in a high risk decile. The White Paper speaks vaguely of "cascading delivery" in which higherneed families will be "offered services at a higher dosage". Presumably this refers to health and social services such as maternity care, parenting courses and public nurse visits. The White Paper does not address the possibility that families refusing services because of the shame and anger that may accompany being classified as "high risk", or what the

\footnotetext{
${ }^{71}$ Privacy Commissioner above n 28 at 64.
} 
consequences of such a refusal will be. Any intervention which is mandatory or punitive is extremely inappropriate when there is no evidence of actual abuse. Use of the model also risks the wrong type of intervention being thrust upon families because it does not identify a specific type of abuse or key risk factor.

The implementation of the PRM should be reconsidered and its benefits weighed against these objections. To justify implementation the model's predictive accuracy and the effectiveness of targeted services must outweigh the resulting incursions on the rights of privacy, non-interference, non-discrimination and the presumption of innocence. Implementing measures should minimise interference with these core rights by limiting access to sensitive information, requiring notification that the model is being used (and consent if possible) and ensuring that targeted services are strictly voluntary and offered without judgment.

\section{(c) Effectiveness of the model}

The effectiveness of a PRM in reducing rates of child abuse in New Zealand will depend on its predictive accuracy, its effect on clinical assessments and its ability to steer families into the right type of service for their need.

The proposed PRM has been found to have reasonable accuracy in predicting the likelihood of substantiated abuse. Its predictive accuracy is comparable to that of mammography in predicting breast cancer risk in women without symptoms. ${ }^{72}$ In the model's trial $47.8 \%$ children ranked in the highest decile suffered substantiated maltreatment by the time they were five years old, as opposed to only $1.7 \%$ of children ranked in decile one.

However, the PRM was designed using statistics relating to substantiated maltreatment so may be inadvertently skewed in favour of predicting abuse that is likely to be detected, reported and proved over abuse that is hidden. Furthermore, the model is made to predict caregiver abuse, and does not differentiate between different types of maltreatment. All of these factors mean the PRM has limited use in the context of sexual abuse which is insidious, underreported, often leaves no mark or injury, ${ }^{73}$ is less closely correlated with abuse risk

\footnotetext{
${ }^{72}$ Vaithianathan above $\mathrm{n} 63$ at 357

${ }^{73}$ Charles Felzen Johnson “Child Sexual Abuse”(2004) 364 The Lancet 462 at 464.
} 
factors, ${ }^{74}$ and has a wider variety of perpetrators. If the PRM is used, there is a danger that professionals will rely on the model despite its limited efficacy in the context of sexual abuse, thus allowing more child victims to slip through the cracks. The model's developers have emphasised the model cannot replace comprehensive clinical assessments of abuse and neglect risk, and should be treated as an aid. ${ }^{75}$ Clinicians should be aware of its limitations, especially in relation to sexual abuse risk and should not allow a child's risk rating (or lack of) to undermine their face-to-face assessments.

Most importantly, the Government must not rely on the model to replace the education and training of frontline professionals on the risk factors and signs of sexual abuse. Most children will not be subject to the PRM so it will remain in the hands of frontline workers like teachers and doctors to recognise they may be at risk of abuse. These professionals should be trained to understand the most important variables in the model - the characteristics and conditions which make children more vulnerable to abuse so they may undertake a similar assessment. Doctors and nurses who see children with a parent have insight into qualities inherent in a child, the child's relationship with the parents, and the family's living conditions, thus are in a good position to direct family into an appropriate service without the stigma of the abuse risk rating. The value of introducing support at early signs of stress or poor parenting such as low level verbal abuse or attachment problems is well recognised. ${ }^{76}$ Unlike the PRM, face-toface assessment can identify specific factor(s) causing a child to be vulnerable and channel a family into corresponding services, e.g. counselling for the parent, help with the child's communication skills. This lowers the risk that families will be herded into inappropriate interventions.

\section{Conclusions on the Predictive Risk Model}

From the little information available, the accuracy of the PRM does not justify its implementation. It carries with it a highly discriminatory attitude towards beneficiaries, the likelihood of stigmatising families by suggesting they are likely to abuse, the potential of undermining face-to-face assessments of abuse risk by frontline professionals and the danger of unjustified reliance on an automated ratings, allowing children to slip between the cracks.

\footnotetext{
${ }_{75}^{74}$ Ministry of Social Development above n 1 at 32.

${ }^{75}$ Vaithianathan above $\mathrm{n} 63$ at 354.

${ }^{76}$ Auckland Sexual Abuse HELP (2012) "Submission to the Green Paper for Vulnerable Children".
} 
If the model is nonetheless implemented, it must be part of a comprehensive child protection plan, running alongside other prevention strategies discussed in this paper. To summarise afore-mentioned points, implementing measures must clarify who is to use the PRM, what information other professionals will receive and how it will be conveyed, how health professionals and others should use risk deciles in their clinical assessments, and what the consequences of a high risk decile will be for children and caregivers.

\section{Vulnerable Kids Information System}

The White Paper states the Government's intention to create a new "information sharing platform" which will create a space for the "children's workforce", including health professionals, to enter and view information about children they are working with, creating a clearer picture of a child's interaction with services and their vulnerability as perceived by different professionals. ${ }^{77}$ Adults who pose a risk to children will also be tracked by the system. ${ }^{78}$ This intended move is in response to several high profile cases in which children suffered as a result of poor communication between professionals and agencies which separately held evidence of abuse. ${ }^{79}$

Mel Smith's report into the abuse of a young girl strongly emphasised the importance of information sharing between agencies, taking the strong position that legal limitations, real or perceived, should not limit the sharing of information that may affect a child's wellbeing. ${ }^{80}$ For Smith, child protection should override privacy concerns. The report also highlighted the need for information sharing to go both ways - currently CYF routinely uses section 66 CYPF Act 1989 to gather information from health professionals but rarely issues responses about individual cases or how information has been used. ${ }^{81}$ The proposed information sharing system can counter this imbalance by allowing professionals outside CYF to access an appropriate level of information for their role. This is important in light of Smith's finding that non-legal factors such as such as poor relationships between agencies (particularly CYF and health professionals) and failure to focus on the child also played a substantial part in

\footnotetext{
${ }^{77}$ Ministry of Social Development above n 8 at 78.

${ }^{78}$ Ministry of Social Development above $\mathrm{n} 1$ at 9.

${ }^{79}$ Office of the Children's Commissioner (2000) "Executive Summary of the Report on the Death of James Whakaruru" and Smith above n 15.

${ }^{80}$ Smith above $\mathrm{n} 15$ at 3

${ }^{81}$ Smith above n 15 at 33.
} 
poor information sharing. ${ }^{82}$ The proposed system carries the potential to ease distrust and resentment between CYF and the health sector by giving health professionals more involvement.

Concerns with the system centre on privacy and appropriate use. Despite Mel Smith's assertion that nothing should impede sharing relevant information, this carries a danger of deterring families from approaching services if they fear the information will be shared with other agencies. ${ }^{83}$ As in the case of the PRM, no legal basis for this type of sharing currently exists, but this could be remedied by the development of an AISA between the relevant agencies for the particular purpose. The system will necessarily deal with extremely sensitive information concerning health, family violence and child protection history which should be treated with appropriate delicacy. A compromise was found in the United Kingdom's now abolished Child Protection Register which was managed by a "custodian" - a head social worker. Police and doctors were alerted to who was on the register, but access to specifics was strictly limited. ${ }^{84}$ The register only monitored children who were classified as at risk by a multi-agency conference that typically involved the family as well. ${ }^{85}$. The limitation of the register to at-risk children and the strict privacy controls partially alleviated ethical and privacy concerns around monitoring and sharing information on families. It appears the New Zealand system will carry similar safeguards. The Minister has indicated that the platform will be a secure system only accessible to approved professionals with individual login details and passwords. ${ }^{86}$ According to the White Paper people will be able to view different levels of information according to their roles, and access will be monitored in order to ensure that the system is not used inappropriately. ${ }^{87}$ The platform will be accompanied by a code of conduct on safe information sharing. ${ }^{88}$

Provided that the implementing measures include the afore-mentioned safeguards, the introduction of the proposed Vulnerable Kids Information System is justified despite the fact that an AISA drafted for this purpose will require exemptions from privacy principles. Preventable deaths such as that of James Whakaruru have demonstrated the danger of

\footnotetext{
${ }^{82}$ Smith above $\mathrm{n} 15$ at 3.

${ }^{83}$ Ministry of Social Development above $\mathrm{n} 8$ at 74.

${ }^{84}$ Liz Davies “A \& E Database not the Answer to Child Protection Failings" The Guardian (Online ed, 2013) at 1.

${ }^{85}$ Davies, above n 84 at 1.

${ }^{86}$ Ministry of Social Development above n 1at 10.

${ }^{87}$ Ministry of Social Development above n 1at 10.

${ }^{88}$ Ministry of Social Development above n 1at 10.
} 
professionals working in silos without sharing concerns. Anecdotal evidence suggests that fear of being wrong is a major reason professionals do not report suspicions, ${ }^{89}$ making a platform that allows the recording of unusual observations or concerns all the more important. Several professionals' observations may together paint a clear picture of a child's situation, as they would have in James's case.

\section{Proposed Reporting Measures}

\section{A. Mandatory Child Protection Policies}

\section{The new legislative requirement, and it shortcomings}

The Government's Vulnerable Children Bill introduces a legislative requirement for prescribed state services, DHBs and schools to implement child protection policies. ${ }^{90}$ Most relevant to the role of health professionals is clause 17 which outlines the requirements for DHBs. Each DHB is required to implement child protection policies "as soon as practicable", ensure that it is available on the DHB's website and review the policy every three years. ${ }^{91}$ The same clause places an obligation on DHBs to ensure that funding arrangements and contracts which involve providing services to children are also subject to a child protection policy. ${ }^{92}$ The legislation is extremely sparse in detail only requiring policies to be in writing and include provisions on the identification and reporting of child abuse, in accordance with s15 of the CYPF Act $1989 .{ }^{93}$

The introduction of this legislative requirement changes very little. DHBs are already subject to an obligation to have child protection policies under their funding agreements with the Ministry of Health. ${ }^{94}$ The only real change in this clause is the requirement of three yearly reviews of protection policies. Reviews may be valuable in highlighting if a policy is resulting in over or under-reporting.

\footnotetext{
89 Teresa O'Connor "Protecting Children from Abuse" (2013) 19.3 Kai Tiaki : Nursing New Zealand 14 at 14.

${ }^{90}$ Vulnerable Children Bill 2013 (150-1) (explanatory note).

${ }^{91}$ Vulnerable Children Bill cls 17(a), (b), (c) and (e).

${ }^{92}$ Vulnerable Children Bill cl 17(d).

${ }^{93}$ Vulnerable Children Bill cl 19.

${ }^{94}$ Louisa Jackson "Reporting Child Abuse in the New Zealand Health Sector: An Intervention Lottery for our most Vulnerable Children" (LLB (Hons) Dissertation, Victoria University of Wellington, 2012) at 9.
} 
Drafters of the Bill considered the option of including a legislative requirement For DHB's child protection policies "to have regard to guidance to be issued by the Minister for Social Development, in consultation with the Ministers of Health, Education, Justice and Police". 95 It is unclear why this option was discarded, the only reason given being "potential legal risks". ${ }^{96}$ Such a requirement would have allowed the Ministry to influence the substantive content of child protection policies in order to ensure national consistency and correspondence with approved research, evidence and policies about signs of abuse and appropriate referral processes. The dismissal of this option means that clause 17 completely bypasses the real problem with child protection policies. The issue is not lack of policies; on the contrary it is the sheer number of varied and conflicting protocols imposed on health professionals by DHBs, private entities and professional associations. ${ }^{97}$ Currently, even DHB child protection protocols vary markedly despite the understanding that they are to reflect Ministry of Health National Guidelines. ${ }^{98}$ As Louisa Jackson has highlighted in her analysis of the protocol framework, this inconsistency between different policies results in an "intervention lottery" in which likelihood abuse being recognised and reported depends on the area and service to which the child presents. ${ }^{99}$

\section{An alternative: the development of a national child protection policy}

If the Bill is to address the real problem with child protection policies, it should at the very least be redrafted to include the proposed requirement that DHBs "have regard" to guidance from the MSD. However, a stronger move would be the development of compulsory nationwide child protection policy to apply to all DHBs, private services and professional associations. The Vulnerable Children Bill should be redrafted as parent legislation for such a policy, including the following provisions:

(a) A statement of who is to develop the policy (ideally the MOH and MSD) with provision for interested parties to make submissions on the content

(b) A requirement of review a set amount of time after implementation by DHBs

\footnotetext{
${ }^{95}$ Ministry of Social Development (2013) Regulatory Impact Statement “Vulnerable Children's Bill: Joint Accountability and Shared Responsibility" Wellington, New Zealand at 13.

${ }^{96}$ Ministry of Social Development above n 95 at 18.

${ }^{97}$ Jackson, above $\mathrm{n} 94$ at 8.

${ }^{98}$ Jackson, above $\mathrm{n} 94$ at 20.

${ }^{99}$ Jackson, above n 94 at 13.
} 
(c) A requirement that where health professionals are subject to conflicting child protection protocols from different sources, they follow the compulsory national policy

(d) Provision for DHBs, individual services or professional associations to apply for exemptions from aspects of the policy on the grounds of characteristics or needs unique to their region, service or profession

(e) Provision for DHBs, individual services or professional associations to add to the policy in order to tailor it to their region, service or profession. For example, DHBs may add lists of local services or

The development of child protection policies involves making some big policy calls which are best made at the national level, so it is surprising that DHBs have been left largely free to make their own decisions on such important and controversial issues. Examples of these big issues include the choice between mandatory and voluntary reporting and whether the treatment of adults (e.g. in mental health or addiction services) should trigger a report in respect of their children. DHB policies currently differ on all of these issues. ${ }^{100}$ As well as reflecting the national stance on these questions, policy should cover both substantive and procedural aspects of child abuse identification and intervention including:

(a) The requirement that health professionals take a "child-centred approach".

(b) A list of "risk factors" associated with abuse. These should be distinguished from signs that abuse is already occurring.

(c) Referral process for when risk factors are identified, including a list of specialised services that may help families reduce risk factors or strengthen protective factors. This list can be tailored by DHBs to reflect services in their regions, including NGOs.

(d) A list of physical and behavioural indicators that abuse is already occurring

(e) Reporting process for when abuse is suspected. This must clearly outline:

(i) Whether there is an obligation to report or whether reporting is merely voluntary

(ii) What level of suspicion triggers a reporting duty (if any)

(iii)Whether fears of future abuse should be reported in the same way as suspected abuse

(iv) What ages are covered (upper limit and whether unborn children are included)

(v) Who should be contacted and what information should be provided in the report

${ }^{100}$ Jackson, above n 94 at 13. 
(vi) What to do if the health professional is unsure about the significance of their observations. This should specify who to contact in case of doubt. For example Christchurch NGO START provides over-the-phone advice on whether observed behaviours or injuries are worrying or invite follow-up. ${ }^{101}$

(f) Referral or reporting process if the professional's patient is an adult and they are worried about the safety of children that adult has access to.

Outlining the process which health professionals should follow when they are unsure whether injuries are indicative of abuse or whether the requisite risk threshold for reporting has been met is extremely important. Frontline professionals looking out for children should not have to choose between reporting and inaction; those who are unsure about the significance of their observations should feel able to seek clarification.

DHBs, individual services and professional associations could add more detail to this policy to reflect the characteristics of their particular region, service or profession. For example, hospitals could encourage consultation with the hospital paediatrician, or DHBs could list regional services (including NGOs) which may aid doctors in making reporting decisions. It is also important that there is provision for those bound by the policy to apply for exemptions or modification to the policy where its requirements are ill-suited to their geographic area or service. For example, within the mental health profession there is a strong emphasis on confidentiality and patient relationship and a distrust of reporting requirements. ${ }^{102}$ However, there may be some concern that this attitude is due to misinformation about the affect of reporting on the therapeutic relationship. ${ }^{103}$ A provision allowing a profession or service to apply to exempt themselves from certain requirements would provide some flexibility while requiring the exemption to be backed up by clear principles and evidence rather than bias. While exemptions may add some complexity to the national policy, this system will be clearer than that currently in place. It also allows important policy decisions to be made centrally according to clear principles.

${ }^{101}$ Maggie Tai Rekena and Catherine Gallagher (START) "Helping the Community to Keep Young ones Safe", (Workshop at Imagining the Solution TOAH-NNEST National Hui, Wellington 9 September 2013).

${ }^{102}$ Christina M Rodriguez "Professionals' Attitudes and Accuracy on Chid Abuse Reporting in New Zealand" (2002) 17 Journal of Interpersonal Violence 320 at 336.

${ }^{103}$ Rodriguez above $\mathrm{n} 102$ at 326. 


\section{B. Training for Professionals Working with Children}

\section{Current Problems}

The White Paper has expressed the Government's intention to train all frontline workers, such as doctors and teachers to recognise signs of child abuse. ${ }^{104}$ The importance of training cannot be overemphasised. In his report on the abuse of a young girl Mel Smith expressed alarm that the GP who "M" saw seemed to have no concern about non-accidental injuries, and observed that specialised training in child protection on an annual basis would be valuable for doctors. ${ }^{105}$ Concern has also been expressed by non-government organisations that health practitioners and other professionals working with children are not adequately trained in identifying injuries and behaviour indicative of abuse, and commonly subscribe to myths and fallacies about child sexual abuse. ${ }^{106}$ A free child protection training programme launched by the Safeguarding Children Initiative has already been used by over 2000 professionals from various fields, demonstrating that there is both a thirst for information, and a lack of training in this area. Directors of the programme have identified several factors which prevent the identification of abuse, including a focus on adults rather than children, a lack of understanding of signs of abuse, confusion about privacy law, "optimism" or the belief that parents do not harm their children, and ignorance of the applicable child protection policy. ${ }^{107}$ They reported that after attending the training many professionals realised they had already encountered children in their work that displayed indicators of abuse. ${ }^{108}$

\section{Training Recommendations}

Without adequate training in child protection, other will reforms, such as changes to protection policies, will have no effect. Child protection training should be provided by the $\mathrm{MoH}$ or MSD and clarify all substantive and procedural aspects of effective abuse detection and intervention, including:

(a) An understanding of the national child protection policy (recommended above) including reporting processes

\footnotetext{
${ }^{104}$ Ministry of Social Development above n 8 at 153.

${ }^{105}$ Smith above $\mathrm{n} 15$ at 46.

${ }_{106}$ Auckland Sexual Abuse HELP above n 76 at 17.

${ }^{107}$ O'Connor, above $\mathrm{n} 89$ at 2.

${ }^{108}$ O'Connor, above $\mathrm{n} 89$ at 2.
} 
(b) The principles of the CYPF Act, particularly the "paramountcy principle" and the importance of taking a child-centred approach

(c) What information can be lawfully shared

(d) Injuries and behaviour indicative of abuse. Different types of abuse should be addressed separately

(e) Factors which make a child more vulnerable to abuse, such as lack of bonding with parents, or a disability

(f) Myths about sexual abuse

(g) On-going psychological effects of child abuse

Training should be mandatory for GPs, nurses, paediatricians, teachers, and social workers and available to other types of health professionals If possible region training should be rather than profession based. If professionals from the same region train together it may improve relationships between different fields and help to dispel the distrust which has hindered reporting and information-sharing in the past.

\section{Medical Examinations Following Suspected Sexual Abuse}

The nature of child sexual abuse as the betrayal of trust by a figure on whom the child is (frequently) dependent, combined with the physical interference with the child's body makes survivors vulnerable to retraumatisation through poor healthcare practice. The current system appropriately requires alleged victims to be examined by a sexual abuse specialist, but access and referral issues persist.

\section{A. The Purpose of Medical Examinations}

In cases of alleged or suspected child sexual abuse the child may undergo a medical assessment. Referral may be by Police, Child Youth and Family (CYF), another doctor (for example the child's GP) or a concerned parent. In circumstances where guardian consent may be refused, the CYPF Act can be used to require an examination. A medical examination following a disclosure or concern of sexual abuse has several objectives: to diagnose and treat any injuries or conditions, to record any evidence of the abuse and to reassure the child and 
family, allowing them to begin the healing process. ${ }^{109}$ Neither physical injury nor forensic findings are common, ${ }^{110}$ so emphasis is placed on the aim of reassuring the child that their body is not harmed, that they are "normal" and addressing their other concerns. ${ }^{111}$

\section{B. The Effect of Medical Examinations on Abused Children}

There is some disagreement as to whether a medical examination following alleged sexual abuse is likely to retraumatise an abused child. ${ }^{112}$ For those that believe medical examinations (especially genital and anal) have a traumatising effect, such procedures are harder to justify, especially if primarily motivated by the hope of collecting evidence of the abuse. This concern may be held by parents, social workers or even health professionals themselves, affecting whether children are referred and assessed. ${ }^{113}$ Some factors out of a doctor's control which may affect a child's response to medical examination are the severity of the abuse and injury, the frequency of abuse and the age of the child. ${ }^{114}$ However one recent study found that medical assessments are generally not as stressful for children as their parents fear and unlikely to retraumatise, provided they are carried out in an appropriate manner. ${ }^{115}$ Evidence to support the belief that children perceive medical examinations as revictimisation is lacking. ${ }^{116}$

National organisation Doctors for Sexual Abuse Care (DSAC) emphasises the role of the medical exam in the promotion of the abused child's physical and mental health, especially the reassurance that a doctor can provide. DSAC patient information states that each step of an examination will be explained to the child and will not proceed until the child consents. Parental consent to the process is necessary, but not alone sufficient. ${ }^{117}$ If medical examinations are carried out in the manner prescribed by DSAC there is very little chance of retraumatisation. In fact, a doctor who is sensitive to the possible vulnerabilities of an abused

\footnotetext{
${ }^{109}$ Britton above $\mathrm{n} 12$ at 573.

${ }^{110}$ Doctors for Sexual Abuse Care (2012) Patient Brochure: "Help for Children" <www.dsac.org.nz>

${ }^{111}$ Britton, above $\mathrm{n} 12$ at 573 .

112 Britton, above n 12 at 575.

${ }^{113}$ Susan Marks, Robyn Lamb and Dimitra Tzioumi "Do no More Harm: The Psychological Stress of the Medical Examination for Alleged Child Sexual Abuse" (2009) 45 Journal of Paediatrics and Child Health 125 at 125.

${ }^{114}$ Linda Whitney Peterson, Zenoa Meservy, Sheila Enos Furth, Xanna Morris, Kathryn Peele and Antoinette Cortese "The Stress of Child Sexual Abuse Examinations" (1994) 1 Journal of Clinical Forensic Medicine 13 at 14.

${ }^{115}$ Marks, Lamb and Tzioumi, above n 113 at 129.

${ }^{116}$ Britton, above n 12 at 576.

${ }^{117}$ Doctors for Sexual Abuse Care above n 110.
} 
child such as impaired body image and sense of powerlessness can facilitate the healing process by restoring to the child control over his or her own body. ${ }^{118}$ Conversely, if control is taken away from the child, consent is not sought or the child is given the impression that the examination is taking place because their disclosure is not believed, further damage may occur as a result of re-experiencing the powerlessness of abuse. ${ }^{119}$ This highlights the importance of the medical examination being carried out sensitively by a practitioner who is aware of the impact of child sexual abuse and the affect of his or her own manner on the child's ability to heal.

\section{Legislative provisions}

The CYPF Act provides for medical examinations to be ordered by the Court or arranged by social workers in certain circumstances. The police may also refer a complainant to a medical examination after disclosure of recent sexual abuse or assault, although they cannot compel examination except through court order. Examinations may also be arranged outside the Act between parents and medical practitioners.

Under s 49 CYPF Act the Court may order an examination if it is satisfied there are reasonable grounds for suspecting that a child is suffering abuse, and an examination may determine whether the suspicion is well-founded. ${ }^{120}$ Applications to the Court may be made by social workers and police constables, ${ }^{121}$ and the Court may grant an ex parte order if notice is likely to prejudice the investigation or create delay which may put the child' safety at risk. ${ }^{122}$ This section can be used to override caregivers' refusal to consent to treatment or in cases where the caregiver is the suspected abuser and may be able to conceal signs of abuse if given notice of the examination. The Court may specify conditions, including the nature of the examination, and the examining doctor must provide a report to the Court on the results. $^{123}$

Under s 53 a social worker may arrange a medical examination if a warrant has been issued under s 39 to search for and remove the child, or if the child has been placed in the custody of

\footnotetext{
${ }^{118}$ Britton, above n 12 at 578.

${ }^{119}$ Britton, above n 12 at 578 .

${ }^{120}$ Section 49(1).

121 Section 49(2).

122 Section 50.

${ }^{123}$ Section 52.
} 
the chief executive under s 39,40 or $42 .{ }^{124}$ The social worker must make reasonable efforts to obtain the consent of the child's caregiver, but if unsuccessful may nonetheless require an examination to be undertaken. ${ }^{125}$

While the Court has wide power to specify the nature of a court-ordered examination and the way in which it is carried out, a s 53 examination requested by a social worker is subject to several limitations. An examination arranged under s 53 must not include any internal examination of genitals or anus of a child unless the medical practitioner believes that the child may have been subject to physical or sexual abuse involving one of these areas, and the child consents to the examination. ${ }^{126}$ The latter condition does not apply if the child's age or maturity makes obtaining consent impracticable. ${ }^{127} \mathrm{~S} 54$ further provides that a child undergoing a s 53 examination is entitled to have a nominated adult present. Powers of the Court and social workers are also qualified by the requirement that in all matters relating to the application of the Act, the welfare and interests of the child are the paramount consideration. $^{128}$

These sections represent a departure from the general rule that consent is needed for medical treatment. The s 49 requirements ensure the Court has determined the expediency of an examination before an order is made, while s 53 sets out certain circumstances in which a medical examination may be justified, while giving social workers discretion as to when their power is exercised. These sections, and the requirement that decision-makers apply the "paramountcy principle", work to ensure that medical examinations are not undertaken unnecessarily or for the wrong reasons. Examinations of genitalia are subject to even more safeguards, reflecting their intimate nature and potential to retraumatise. As already noted, unless ordered by the Court, genital examinations are subject to necessity and the child's consent.

\footnotetext{
${ }^{124}$ Section 53.

${ }^{125}$ Section 53.

${ }^{126}$ Section 55(1).

127 Section 55(3).

${ }^{128}$ Section 6.
} 


\section{Child or Young Person's Consent or Refusal of Medical Examination}

\section{Consent to general medical examinations}

The Care of Children Act provides that 16 and 17 year olds have the same capacity as adults to consent to and refuse medical treatment. ${ }^{129}$ This means that a court order under s 49 cannot be used to override a 16 or 17 year old's refusal to undergo a medical examination, ${ }^{130}$ nor can a parent or guardian consent on their behalf. However, the relationship between section 49 and relevant common law is more ambiguous. Lower New Zealand courts have approved $^{131}$ the English House of Lords' statement in Gillick that under the common law, the parental right to determine whether their child receives medical treatment terminates when a child achieves "sufficient understanding and intelligence to understand fully what is proposed". ${ }^{132}$ This case law makes it clear that a Gillick competent child may consent to a medical examination against a guardian's wishes. However, it is unclear if a Gillick competent child refuses to undergo an examination, whether section 49 can be used to override this lack of consent.

English and Australian courts have indicated that they retain the right to override the refusal of medical treatment by a Gillick competent child. ${ }^{133}$ While these cases related to the exercise of the Court's parens patriae jurisdiction, it is likely that the same principle will apply to the use of statutory powers. Given that a Gillick competent child is by definition capable of making informed medical decisions, (and may in reality be more capable than a person with statutory competence) the judiciary's insistence on retaining the power to override refusals is not principled. ${ }^{134}$ Rather it reflects the extreme nature of the cases which gave rise to the rule and judges' eagerness to find a legal avenue by which to order life-saving treatment.

\footnotetext{
${ }^{129}$ Care of Children Act 2004 s 36.

${ }^{130}$ Practicecentre.cyf.govt.nz Policy - "Caring for Children and Young people".

${ }^{131}$ Re SPO FC Wellington FAM 2004-085-1046, 3 November 2005.

${ }^{132}$ Gillick v West Norfolk Area Health Authority [1986] 1 AC 112 (UKHL) at [189].

${ }^{133} \operatorname{Re} R$ (A Minor) (Wardship: Consent to Treatment) [1992] Fam 11 (CA) and Director General, New South Wales Department of Community Services v $Y$ [1999] NSWSC 644 as cited in Adam Holloway "Who Holds the Key to Medical Treatment? A Guardian's Ability to Consent on Behalf of a Competent Child under the Age of Sixteen" (LLM Paper, Victoria University of Wellington 2013).

${ }^{134}$ See Holloway above $\mathrm{n} 133$ for discussion.
} 
It is likely that if faced with such a decision New Zealand courts will also take the view that they may override Gillick competent refusal of treatment, whether through parens patriae jurisdiction, or statutory orders. However, given the extreme circumstances in which this rule developed overseas, it is unlikely that s 49 will be used to countermand the refusal of a medical examination except in the most compelling cases. The Supreme Court of New South Wales has emphasised that that the power of the Court to override the child's wishes "is to be exercised sparingly and with great caution". ${ }^{135}$ If New Zealand courts adopt a similar approach, s 49 will be available but unlikely to be used to compel a Gillick competent child to undergo examination unless there is a significant risk to life or health, such as serious injury or infection. The same conclusion would result from a correct application of the paramountcy principle, balancing the health implications of failing to undergo examination against the psychological effects of informed consent being overridden.

\section{Consent to genital and anal examinations}

As outlined earlier, s 55 requires the child's consent to be obtained if an examination requested by a social worker under $\mathrm{s} 53$ is to include an internal genital or anal examination. ${ }^{136}$ However, this requirement need not be fulfilled if the child's age or level of maturity makes it impracticable to obtain such consent. ${ }^{137}$ It is unclear whether this requirement is a statutory restatement of Gillick, or whether a child who is not Gillick competent is able to refuse consent under this section. It is foreseeable that medical practitioner may be confronted by a child who does not fully understand the process of internal examination or its health and forensic benefits, but is frightened and expresses a strong preference not to be examined.

Analysis of the purpose of s 55 can aid in its interpretation. The requirement that the child's consent is obtained can be seen as a legislative acknowledgment of the potentially retraumatising effect of the intimate examination. It minimises the risk that the examination will cause child to re-experience the feelings of powerlessness associated with abuse by giving the child control over this aspect of the procedure. If this is accepted as the purpose of s 55, it follows that consent is important regardless of whether the child is Gillick competent.

\footnotetext{
${ }^{135}$ Director General, New South Wales Department of Community Services $v$ Y above n 133.

${ }^{136}$ Section 55(1).

137 Section 55(3)
} 
Overriding a child's refusal to consent to intimate touching is damaging whether or not the refusal is expressed with full information and understanding.

For the reasons above, s 55 should be interpreted to require consent from any child capable of articulating a preference. This interpretation does not preclude overriding a child's refusal in all circumstances. As the s 55 consent requirement only applies to social-worker requested examinations under s 53, a court-ordered examination may still be used to compel an unwilling child to undergo an intimate examination. This should be a last resort, as ideally all intimate examinations will be carried out by doctors with an understanding of the effects of sexual abuse and training in reassuring children and obtaining the requisite consent. This interpretation is also consistent with medical practitioners' duty to minimise distress to children when performing medical examinations under the Act. ${ }^{138}$

Sections 49 and 53 ensure examinations can only be ordered in certain circumstances, and are performed for the benefit of the child. This is particularly important in cases of sexual abuse where there may be a tension between investigators' interest in forensic evidence and the child's wishes not to be examined. In Pettus v $R$ the Court emphasised that $\mathrm{s} 53$ should be used only by social workers when the elements of the section are met and medical examination is in the interest of the child. ${ }^{139}$ It criticised Police interference in the process which resulted in the children's welfare and best interests becoming secondary to the interests of the investigation. ${ }^{140}$ In response to the claim that a "medical examination" should not include the taking of samples, the Court placed the decision as to the appropriate type of examination in each case in the hands medical practitioners, emphasising that this is not a decision for Police to make. ${ }^{141}$ The Pettus decision may force medical practitioners to stand in the path of investigators to protect children from examinations that are not in their best interests. In some cases a medical practitioner's decision will involve complex considerations such as whether the desirability of collecting forensic evidence to bring a perpetrator to justice should be part of a "best interests" analysis. The weight of these decisions makes it all the more important that examining practitioners are fully aware of children's rights and their own duties under the CYPF Act.

\footnotetext{
${ }^{138}$ Child, Young Persons, and their Families Act s 12.

${ }^{139}$ Pettus v $R$ [2013] NZCA 157 at [41].

${ }^{140}$ At [43].

${ }^{141}$ At [43].
} 


\section{E. Requirements for Doctors Conducting Medical Examinations Following Sexual Abuse}

In New Zealand it is expected that medical assessments following alleged abuse will only be carried out by doctors with training and expertise in sexual abuse. This is not a legislative requirement, but is adhered to as much as possible. The Police require doctors to have DSAC accreditation or equivalent in order to carry out such assessments, and CYF and other doctors will also refer to accredited doctors. ${ }^{142}$ Non-accredited general practitioners are advised to refer suspected child sexual abuse to CYF or the Police rather than carrying out genital examinations themselves. ${ }^{143}$ It is appropriate that expertise be required for such intimate examinations with vulnerable patients. DSAC's policy of obtaining consent throughout the examination process is consistent with practitioners' legislative duties, and extends similar protection to children whose examinations are arranged outside the Act. Accredited doctors are more likely to be sensitive to risk of retraumatisation and understand the legislative environment in which they are working. They are also capable of collecting forensic evidence and providing expert testimony.

\section{F. Recent Developments: Sexual Abuse Assessment and Treatment Services}

The 2008 introduction of Sexual Abuse Assessment and Treatment Services (SAATS) has partially improved access to accredited doctors. SAATS is a medical service for survivors of sexual assault or abuse which is jointly funded by ACC, the NZ Police and the Ministry of Health through contracts with individual DHBs. ${ }^{144}$ The service has no legislative status, so its effectiveness relies on the extent to which DHBs' contractual obligations are met. The service is designed to provide triage, assessment, treatment and referral services twenty-four hours a day for alleged victims of sexual assault or abuse of any age or gender. ${ }^{145}$ It aims to improve sexual abuse treatment by providing better access to doctors with expertise, ensuring assessments are conducted in suitable environments and increasing coordination between doctors, Police CYF and crisis agencies through referral processes. ${ }^{146}$ Medical assessments continue to be provided by DSAC accredited doctors. ${ }^{147}$ All DHBs except South Canterbury

\footnotetext{
${ }^{142}$ Everitt, Reed and Kelly, above 5 at 389.

${ }^{143}$ NZCYPS "Breaking the Cycle: Interagency Protocols for Child Abuse Management" (1996) at 4-8.

${ }^{144}$ ACC website "Sexual Abuse Assessment and Treatment Services (SAATS)" <www.acc.co.nz>.

${ }^{145}$ ACC above $\mathrm{n} 144$.

${ }^{146}$ Controller and Auditor General "Response of the New Zealand Police to the Commission of Inquiry into Police Conduct: Third Monitoring Report" (2012).

${ }^{147}$ ACC above n 144.
} 
are now contracted into SAATS, ${ }^{148}$ so if implementation goes as planned the benefits of the new service will be almost nation-wide.

\section{Room for improvement}

It is hoped that SAATS will bring more national consistency to the provision of sexual abuse treatment, but great variance in the quality of services throughout New Zealand currently remains. One study published in 2011 found that health assessments of sexually abused children were infrequent and nationally inconsistent. ${ }^{149}$ Common problems were lack of coordination between the health system and CYF or Police, shortage of paediatricians, social workers or adequate facilities or failure to provide for after-hours assessments. ${ }^{150}$ This information was gathered very early after the introduction of SAATS, so services are likely to improve as DHBs continue to implement and work on their obligations under SAATS contracts. One concerning finding was the low quality of treatment services (ranked 2/10) provided by the South Canterbury DHB. ${ }^{151}$ This finding remains relevant as South Canterbury is the only DHB yet to contract into SAATS, making it likely that services have not improved since the study took place. This district has recently been singled out as one in which victims' access to specialist medical assessment and treatment is particularly poor. ${ }^{152}$ Where expertise and resources are scarce it is unknown how many victims are travelling long distances for assessment, being examined by non-DSAC doctors or missing out on medical attention altogether. ${ }^{153}$ The Police have now indicated that resolving issues with the South Canterbury DHB with the aim of implementing SAATS is a priority. ${ }^{154}$

\section{Low rates of referral to treatment}

Improved treatment services will be of limited effect if referral rates do not reflect need. In 2004 DSAC expressed concern that, although CYF was dealing with more cases of alleged child sexual abuse, the number of children being referred to DSAC doctors for assessment

\footnotetext{
${ }^{148}$ Controller and Auditor General above n 146.

${ }^{149}$ Everitt, Reed and Kelly, above n 5 at 393.

${ }^{150}$ Everitt, Reed and Kelly, above $\mathrm{n} 5$ at 391.

${ }^{151}$ Everitt, Reed and Kelly, above $\mathrm{n} 5$ at 393.

${ }^{152}$ Controller and Auditor General above n 146.

${ }^{153}$ Caroline Corkill and Carol Shand (eds) DSAC National Newsletter (2004) No 57 at 4.

${ }^{154}$ NZ Police, Police Quarterly Summary, December 2012.
} 
was decreasing. ${ }^{155}$ In 2011 medical assessments remained infrequent, conducted in less than $40 \%$ of child sexual abuse cases substantiated by CYF. ${ }^{156}$ More information is needed to determine whether these rates of referral are a cause for concern. Where disclosure of abuse is significantly delayed, internal examination is generally unhelpful. On the other hand, it is concerning if victims of recent or violent abuse who are in need of medical attention are experiencing barriers to care.

\section{Legislative Barriers}

Low referral rates may be partially attributable to the legislative hurdles that must be overcome before the s 53 power to arrange an examination can be exercised by social workers. As outlined before, these requirements are aimed at protecting children from unwarranted examinations. However, it is possible that they are acting as barriers between children and medical treatment which is badly needed.

One solution is to amend s 53 to draw a distinction between medical examinations arranged with parental consent and those required by a social worker notwithstanding refusal of consent. A possible re-drafting, taking into account earlier discussion about competence and practitioners' qualifications follows:

The current s 53(2) should become a stand-alone section:

"53 A social worker, with the consent of any parent or guardian of a child or young person, or the consent of child or young person competent to make this decision, may arrange for any child or young person to be medically examined by a medical practitioner"

This would leave the current s 53(1) requirements to apply only to examinations to which parents have refused consent:

“53A (1) This section applies to any child or young person-

(a) in respect of whom a warrant has been issued under section 39; or

(b) who is placed in the custody of the chief executive under that section or under section 40 or section 42.

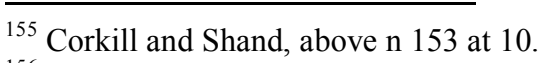

${ }^{156}$ Everitt, Reed and Kelly, above n 5 at 393. 
(2) Where, after making reasonable efforts to do so, a social worker does not obtain the consent of a parent or guardian of a child or young person to a medical examination, a social worker may require the child or young person to be medically examined by a medical practitioner"

Such an amendment will allow social workers to aid parents by arranging medical examinations when parents are cooperative but overwhelmed by a disclosure of abuse and unsure how to proceed. Children will still be safeguarded by the duties on social workers and medical practitioners to regard the child's welfare and best interests as paramount in the exercise of their powers, which will become slightly stronger with enactment of the Vulnerable Children Bill and the creation of the recommended child-centred national policy. The limitations on internal genital examinations in s 55 would also continue to apply. A requirement that genital and examinations must be carried out by a DSAC accredited practitioner could be added to this section. This amendment would strike a better balance between access to care and protection from inappropriate treatment. It may also promote a healthier relationship between CYF and parents if social workers are able to support parents who are faced with a disclosure of abuse, rather than acting only when a warrant or custody order is in force against parents.

\section{Inter-agency communication}

Communication between CYF, Police, ACC and health professionals has been poor despite the emphasis on collaboration in both national and international child protection guidelines. ${ }^{157}$ There may be many reasons for failure to refer to a doctor - parents, social workers or police may see an examination as potentially harmful or dismiss it as unnecessary if time has passed, making the finding of forensic evidence unlikely. This attitude discounts the value of reassurance and empowerment a doctor can provide as well as the importance of ensuring the child gets a general health check-up when he or she comes to the attention of child protection services. Children who have suffered sexual abuse are more likely to have undiagnosed conditions or unmet health needs than the general paediatric population. One

\footnotetext{
${ }^{157}$ Everitt, Reed and Kelly, above n 5, citing The DSAC Medical Management of Sexual Assault $6^{\text {th }}$ ed 2006 and NZCYP Service "Breaking the cycle - Interagency protocols for child abuse management".
} 
study found that in medical assessments of alleged child sexual abuse victims, medical diagnoses unrelated to the abuse were even more frequent than abuse-related findings. ${ }^{158}$

Police and CYF social workers should be educated in the importance of referral and the benefits of medical assessment by a doctor who understands the effects of sexual abuse. In particular, the Police must go beyond the focus of their investigation to develop a culture of promoting child welfare through referral even when forensic findings are unlikely. As already emphasised, it should be in the hands of a medical professional rather than Police to determine whether and what type of medical examination is necessary given the circumstances. ${ }^{159}$ One author described the attitudes of DHBs and CYF as reinforcing a "culture" of regarding sexual abuse services as an "optional extra". ${ }^{160}$ Hopefully the roll-out and funding of SAATS by state agencies conveyed the message that such a service is not an extra but a necessity. SAATS requires doctors to refer to CYF, Police, ACC and crisis agencies but reciprocity is needed from these agencies to ensure children receive the new benefits of the service. The Police have been criticised for failure to refer to specialist services and their inconsistent handling of sexual abuse complaints ${ }^{161}$ which has prompted them to focus more on sexual abuse training. ${ }^{162}$ Hopefully, as SAATS become more established referral processes will become engrained and less likely to be affected by individual perceptions of medical examinations as stressful or harmful.

\section{For the future}

The effectiveness of SAATS remains to be seen, but its emphasis on access, referral and follow-up is promising. Improving rates of assessment, and coordination between agencies generally, should be a priority - this may be achieved by training CYF social workers and police officers in the importance of medical assessment and establishing a practice of consulting with a DSAC doctor. This does not mean that an examination will be performed in every case, but provides an opportunity for a trained medical professional to assess whether examination, treatment or further referral (for example, to therapy) is necessary. Public

\footnotetext{
${ }^{158}$ However, it should be noted that this study took place in the United States. Rebecca Giradet, Laura Giacobbe, Kelly Bolton, Sheela Lahoti and Margaret McNeese "Unmet Healthcare Needs among Children Evaluated for Sexual Assault" (2006) 160 Archives of Paediatrics and Adolescent Medicine 70 at 70.

${ }^{159}$ Pettus $v R$ above $\mathrm{n} 139$.

${ }^{160}$ Everitt, Reed and Kelly, above n 5 at 393.

${ }^{161}$ Controller and Auditor General above n 146.

${ }^{162}$ NZ Police, Police Quarterly Summary, December 2012.
} 
education may also help to dispel parents' fears that medical examinations will be too stressful for their child.

\section{Health Care for Adult Survivors of Child Sexual Abuse}

The section addresses the often neglected needs of adult survivors of child sexual abuse. While it is expected that children who experience sexual abuse will be seen by an accredited doctor, there is no such provision for the general healthcare of adult survivors, so their later complaints may be assessed by doctors who do not recognise the significance of a history of sexual abuse.

Given the high prevalence of child sexual abuse in New Zealand and the serious and enduring effects on its survivors, there is need for appropriate health care for the many survivors throughout their lives. The relevance of child sexual abuse to the health care system is not limited to abuse-specific medical examinations and treatment; adult survivors need their general health care to be provided in a sensitive manner which recognises that their experience may affect how they respond to doctors, medical settings, and medical procedures.

\section{A. The Enduring Effects of Child Sexual Abuse}

Survivors of child sexual abuse are affected differently by their experience depending on a raft of factors such as the severity of the abuse, how well they remember it, their relationship with the perpetrator and whether their trauma was ever disclosed or "resolved". A number of physical and psychological conditions have been attributed wholly or partly to childhood abuse, some of which are temporally remote and may not be recognised by the patient as stemming from their childhood experiences. ${ }^{163}$ Physical effects range from those easily linked with abuse such as sexual, gynaecological and reproductive problems to those that are harder to explain such as heart disease, cancer, liver disease, obesity and medically unexplained conditions. ${ }^{164}$ The direct cause of some of these complaints may be abuse-related

\footnotetext{
${ }^{163}$ Kirsten Havig "Health Care Experiences of Adult Survivors of Child Sexual Abuse: A Systematic Review of Evidence on Sensitive Practice" (2008) 9 Trauma, Violence, Abuse 19 at 20.

${ }^{164}$ Havig, above n 163 at 21.
} 
psychological trauma which has caused the survivor to engage in "self abuse" (self-harm, substance abuse and risky behaviours) ${ }^{165}$ or to avoid medical care. ${ }^{166}$

\section{B. The Relevance of Child Sexual Abuse History to Health Care}

A patient's history of sexual abuse is relevant to their later health care for several reasons: Firstly, their complaint may be linked to or caused by the abuse they suffered, although they do not recognise the connection. Secondly, their experience of abuse is likely to affect how they approach and respond to health care, including whether they seek care when it is needed and their reaction to authoritative figures, medical examinations and medical environments. ${ }^{167}$ The risk of retraumatisation is not limited to the abuse-specific medical examination - if survivors are unable to express their discomfort during medical procedures retraumatisation can occur during the provision of general healthcare long after the abuse. ${ }^{168}$ Although revictimisation can occur in any aspect of the survivor's life, the doctor's visit has special potential to parallel the abuse - the presence of an authority figure, touching, pain or feelings of loss of control. ${ }^{169}$ Thirdly, survivors of child sexual abuse are at risk of being revictimised by the abuse of exploitive professionals, including therapists and doctors. This has been called "sitting duck syndrome". ${ }^{170}$ There is a clear need for health professionals to understand how a history of sexual abuse may impact the patient's diagnosis, response to the medical setting and vulnerability to unprofessional conduct.

\section{What Survivors Want}

A New Zealand study of survivor's views on their experiences with health professionals found that inquiry about sexual abuse and a supportive response upon disclosure were highly valued. Survivors commonly feel unable to disclose their history of abuse to doctors because

\footnotetext{
${ }^{165}$ Martha Bala "Caring for Adult Survivors of Child Sexual Abuse: Issues for Family Physicians" (1994) 40 Canadian Family Physician 925 at 928.

${ }^{166}$ Havig above $\mathrm{n} 130$ at 21.

${ }^{167}$ Kim McGregor, Marewa Glover, Jenny Gautam and Shirly Julich "Working Sensitively with Child Sexual Abuse Survivors: What Female Child Sexual Abuse Survivors Want from Health Professionals (2010) 50 Women and Health 737 at 739.

${ }^{168}$ McGregor, Glover, Gautam and Julich above n 167 at 739.

${ }^{169}$ McGregor, Glover, Gautam and Julich above n 167 at 739.

${ }^{170}$ Estelle Disch "Sexual Victimisation and Revictimisation of Women by Professionals: Client Experiences and Implications for Subsequent Treatment” (2006) 29 Women and Therapy 41 at 42.
} 
of shame, fear or doubt as to its relevance. ${ }^{171}$ Therefore, it was seen as important for a doctor to actively provide opportunities for disclosure and create an environment in which the patient feels safe. Survivors also felt that their health care experience could be improved if professionals - especially GPs, gynaecologists and maternity service providers - were trained in the effects of child sexual abuse by agencies specialising in sexual abuse. Training would ideally cover the difficulty of disclosing abuse, the varying effects and the fact that survivors may find certain procedures harder or likely to trigger memories of abuse. ${ }^{172}$ Other publications have encouraged family physicians to familiarise themselves with how to detect "disguised" presentations of sexual trauma in order to identify and aid survivors. ${ }^{173}$

\section{Survivors' Suggestions and Possible Alternatives}

Given that one in four female patients is a survivor of child sexual abuse, doctors should be aware of the possibility of a history of abuse and practice in a sensitive manner which will not retraumatise. Several options are available:

(a) Information about the experiences of survivors could be included in the training of professionals recommended earlier. This should cover how the needs and experiences of adult survivors differ from children, and ways in which childhood trauma may manifest itself in the healthcare setting

(b) Encouraging GPs to make patients' past experiences, including possible child sexual abuse, part of routine questioning. Many survivors want their doctor to know about their history but feel unable to initiate disclosure. ${ }^{174}$ A measure as simple as displaying DSAC brochures may indicate to patients that the doctor is equipped to respond to abuse-related trauma. ${ }^{175}$ This may be encouraged in training, or set out in the national child protection policy to require routine questioning about abuse or past trauma as part of the general health assessment

(c) Developing guidelines in specific fields like gynaecology to include information on the relevance and management of the patient's history of sexual abuse. The UK's Guidelines for Gynaecological Examinations emphasise the importance of gentleness, consent, awareness of

\footnotetext{
${ }^{171}$ McGregor, Glover, Gautam and Julich, above n 167 at 738.

${ }^{172}$ McGregor, Glover, Gautam and Julich above n 167 at 744

${ }^{173}$ Bala, above n 163 at 925.

${ }^{174}$ McGregor, Glover, Gautam and Julich, above n 167 at 744.

${ }^{175}$ McGregor, Glover, Gautam and Julich, above n 167 at 744.
} 
signs of distress and opportunities to disclose any difficulties or traumas. ${ }^{176}$ An explanation of the power imbalance between patient and doctor and how to return control to a patient may be a useful addition. For specific areas of health care to which sexual abuse is highly relevant (such as gynaecology and maternity services) it may be more appropriate to require practitioners to undertake more in-depth training in child sexual abuse survivors' needs.

While survivors understandably feel that health professionals should be alert to symptoms of possible child sexual abuse and its on-going effects, this must be balanced against the consideration that GPs are already required to have vast knowledge. However, it is necessary and achievable for all doctors to be trained to practice sensitively and understand basic principles of consent, power dynamics and creating safe environments. These principles should be applied to all patients and will help to ensure that GPs do not inadvertently retraumatise survivors, even if they are not equipped to recognise their symptoms. Increasing the awareness of GPs and other health professional of the on-going consequences of child sexual abuse may aid in a more general understanding of the psychological causes of physical ailments and aid patients who have experienced other types of trauma or mental illness to also receive a more complete assessment and diagnosis.

\section{The Bigger Picture}

The health profession's role in child abuse intervention and treatment represents only a small part of addressing New Zealand's child abuse "epidemic" and appalling rates of sexual abuse. While the White Paper and Vulnerable Children Bill make some valuable moves towards the identification of at-risk children, they do not address the root causes of abuse. The White Paper has been criticised for narrowing the focus of reform from whether the whole system is providing children with what they need at the start of life such as good health, education and housing, to identifying families where abuse is likely. ${ }^{177}$

\footnotetext{
${ }^{176}$ Royal College of Obstetricians and Gynaecologists Gynaecological Examinations: Guidelines for specialist practice, July 2002.

177 "Predicting Trouble: Child Abuse Database Raises Eyebrows" The New Zealand Herald (20 October 2012) at 1 .
} 
The identification of children who are vulnerable or parents who are a cause for concern is important, but these families will not decrease in number unless reforms are made to attempt to tackle underlying causes for risk such as poverty, stress, unemployment, substance abuse and the lack of self-worth that come with the stigmatisation these situations. The PRM in particular runs the risk of adding to this stigma by focusing solely on the children of beneficiaries. A recent University of Otago study has found that about 34000 people in New Zealand suffer "severe housing deprivation", about a quarter of which are children. ${ }^{178}$ Families in this situation are unlikely to meet any of the basics that children require, and in stressful and humiliating circumstances adults become their worst selves, increasing the likelihood of abuse. Furthermore, children with no fixed abode are unlikely to be receiving adequate education or healthcare, making the role of health and education professionals in intervening in abuse ineffective for this group of children. For these reasons, measures to "catch" abusers or potential abusers are ineffective if they are not accompanied by efforts to address the reasons why these people pose a risk.

The characterisation of child sexual abuse in the White Paper as largely a result of the perpetrator's aberrant sexual desires is also unhelpful because it denies social and environmental factors that contribute to abuse and denies society's responsibility to change the culture of abuse and "rape mythology" that prevail in New Zealand. Auckland Sexual Abuse HELP advocates both mandatory training for professionals and public campaigns to raise awareness about the prevalence of sexual abuse and dispel dangerous and offensive misconceptions such as "stranger-danger" being the biggest threat, the concept of child "seductresses", that children will always disclose abuse and that family problems are personal and no one else's business. ${ }^{179}$

When these matters are considered it becomes clear that intervention and treatment are only the tip of the iceberg in New Zealand's response to abuse. The role of health professionals is extremely important, but they form part of a larger framework of protection which is in turn affected by bigger social policy considerations.

\footnotetext{
${ }^{178}$ Ben Heather "Being Homeless Hits Children Hard" The Dominion Post (24 September 2013) at 1.

${ }^{179}$ Auckland Sexual Abuse HELP above n 76 at 3.
} 


\section{Conclusion}

Health professionals are subject to a complex framework of legislative provisions, policy requirements, informal systems and expectations in their child protection role. Their decisions are affected by both broad legislative principles and specific guidelines and policies, some of which overlap and conflict. The White Paper and Vulnerable Child Bill put more power into the hands of health professionals by proposing greater access to information from which to make decisions and taking down some of the barriers posed by privacy law. This paper concludes that while the proposed information sharing platform is a proportional incursion on privacy, the PRM is not and should be discarded in favour of making face-to face assessments as accurate as possible. This is particularly important in the context of sexual abuse for which a risk modelling designed to assess the risk of abuse generally may not be accurate. Training is the most important aspect of quality clinical assessments, and a national child protection policy would support this by providing clear guidelines as to how to act when observations trigger concern.

The provision of medical examinations following child sexual abuse is appropriately expected to be carried out by a DSAC doctor. This expectation could be strengthened by incorporating it into section $55 \mathrm{CYPF}$ Act as a legislative requirement. There is also room to amend legislative provisions relating to examinations to allow social workers to help families arrange examinations, and to give children the power to consent to examinations themselves if they are competent to do so. The introduction of SAATS provides hope that more children will have access to appropriate care after experiencing abuse. Finally, the position of adult survivors is often neglected and calls for more consideration. Information on the experiences of adult survivors could be incorporated into mandatory training on child sexual abuse, or placed in guidelines for certain professions. Health professionals are a key part of the children's workforce, and are involved in every stage of ensuring child wellbeing. Legal provisions relating to their role should allow them to protect children to the best of their ability, while balancing other rights and interests of parents, the state and the children themselves. As can be seen, this is no easy task. 
XII. Bibliography

\section{A. Cases}

1. New Zealand

Pettus v $R$ [2013] NZCA 157.

Re SPO FC Wellington FAM 2004-085-1046, 3 November 2005.

2. Australia

Director General, New South Wales Department of Community Services v Y [1999] NSWSC 644

\section{United Kingdom}

Gillick v West Norfolk Area Health Authority [1986] 1 AC 112 (UKHL) at [189].

$\operatorname{Re} R$ (A Minor) (Wardship: Consent to Treatment) [1992] Fam 11 (CA).

\section{B. Legislation}

Privacy Act 1993.

Privacy Amendment Act 2013.

\section{Books and Chapters in Books}

Judith Daylen, Wendy van Tongeren Harvey and Dennis O'Toole Trauma, Trials and Transformation: Guiding Sexual Assault Victims through the Legal System and Beyond (Irwin Law, Toronto, 2006).

Mark Henaghan and Bill Atkin (eds) Family Law Policy in New Zealand $\left(3^{\text {rd }}\right.$ ed, Lexis Nexis, Wellington, 2007).

\section{Journal Articles}

Charles Felzen Johnson “Child Sexual Abuse”(2004) 364 The Lancet 462.

Estelle Disch" Sexual Victimization and Revictimization of Women by Professionals: Client Experiences and Implications for Subsequent Treatment (2006) 29 Women and Therapy 41.

Helen Britton "Emotional Impact of the Medical Examination" (1998) 22 Child Abuse and Neglect 573 .

Janet Fanslow, Elizabeth Robinson, Sue Crengle and Lana Perese "Prevalence of Child Sexual Abuse Reported by a Cross-sectional Sample of New Zealand Women" (2007) 31 Child Abuse and Neglect 935. 
Kim McGregor, Marewa Glover, Jenny Gautam and Shirly Julich "Working Sensitively with Child Sexual Abuse Survivors: What Female Child Sexual Abuse Survivors Want from Health Professionals" (2010) 50 Women and Health 737.

Kirsten Havig "Health Care Experiences of Adult Survivors of Child Sexual Abuse: A Systematic Review of Evidence on Sensitive Practice" (2008) 9 Trauma, Violence, Abuse 19.

Linda Whitney Peterson, Zenoa Meservy, Sheila Enos Furth, Xanna Morris, Kathryn Peele and Antoinette Cortese "The Stress of Child Sexual Abuse Examinations" (1994) 1 Journal of Clinical Forensic Medicine 13.

Martha Bala "Caring for Adult Survivors of Child Sexual Abuse: Issues for Family Physicians" (1994) 40 Canadian Family Physician 925.

R Gilbert, J Fluke, M O'Donnell “Child Maltreatment: Variation in Trends and Policies in Six Developed Countries" (2012) 379 Lancet 758.

Rebecca Giradet, Laura Giacobbe, Kelly Bolton, Sheela Lahoti and Margaret McNeese "Unmet Healthcare Needs among Children Evaluated for Sexual Assault" (2006) 160 Archives of Paediatrics and Adolescent Medicine 70.

Rhema Vaithianathan, Tim Maloney, Emily Putam-Hornstein, Nan Jiang "Children in the Public Benefit System at Risk of Maltreatment: Identification via Predictive Modelling" (2012) 45 American Journal of Preventative Medicine 354.

Rose Everitt, Peter Reed and Patrick Kelly "Medical Assessment for Child Sexual Abuse: A post-code lottery?” (2011) 48 Journal of Paediatrics and Child Health 389.

Teresa O'Connor "Protecting Children from Abuse" (2013) 19.3 Kai Tiaki : Nursing New Zealand 14.

T Chang, D Runyan, S Bangdiwala and R Agans "Epidemiologic Factors of the Physical and Sexual Abuse of Children in the Carolinas" (2005) 115 Paediatrics 257.

\section{E. Parliamentary and Government Materials}

Mayhew, P and Reilly J (2009), Ministry of Justice, The New Zealand Crime and Safety Survey 2006.

Ministry of Social Development (2013) Regulatory Impact Statement: "Vulnerable Children's Bill: Joint Accountability and Shared Responsibility” Wellington, New Zealand.

Ministry of Social Development (2012) White Paper for Vulnerable Children, Wellington, New Zealand.

Roper T and Thompson A (2006), Estimating the costs of crime in New Zealand in 2003/04, New Zealand Treasury Working Paper 06/04. 


\section{F. Reports and Guidelines}

ACC "Sexual Abuse and Mental Injury - Practical Guidelines for Aotearoa New Zealand" (March 2008)

Auckland District Health Board, Board Policy Manual Section 5: Child Protection Alerts Management (December 2009).

Controller and Auditor General "Response of the New Zealand Police to the Commission of Inquiry into Police Conduct: Third Monitoring Report" (2012).

Law Commission Review of the Privacy Act (NZLC R123, 2011).

Mel Smith "Report to Hon Paula Bennett, Minister of Social Development Following an Inquiry into the Serious Abuse of a Nine Year Girl, and Other Matters Relating to the Welfare, Safety and Protection of Children in New Zealand" 31 March 2011.

NZCYPS “Breaking the Cycle: Interagency Protocols for Child Abuse Management” (1996).

New Zealand Police, Police Quarterly Summary (December 2012).

Privacy Commissioner "Health Information and Privacy Code 1994" (Incorporating Amendments) December 2008.

Royal College of Obstetricians and Gynaecologists Gynaecological Examinations: Guidelines for specialist practice, July 2002.

\section{G. Submissions}

Auckland Sexual Abuse HELP (2012) "Submission to the Green Paper for Vulnerable Children".

Children's Commissioner (2012) "Submission to the Green Paper for Vulnerable Children”.

Doctors for Sexual Abuse Care (2012) "Submission to the Green Paper for Vulnerable Children".

Harmful Sexual Behaviour Sector (2012) "Submission to the Green Paper for Vulnerable Children".

\section{H. Dissertations}

Adam Holloway "Who Holds the Key to Medical Treatment? A Guardian's Ability to Consent on Behalf of a Competent Child under the Age of Sixteen" (LLM Paper, Victoria University of Wellington 2013). 
Louisa Jackson "Reporting Child Abuse in the New Zealand Health Sector: An Intervention Lottery for our most Vulnerable Children" (LLB (Hons) Dissertation, Victoria University of Wellington, 2012)

\section{Internet Sources}

ACC "Sexual Abuse Assessment and Treatment Services Contracted Vendors (July 2010) $<$ www.acc.co.nz>.

ACC "Sexual Abuse Assessment and Treatment Services (SAATS)" <www.acc.co.nz>.

Caroline Corkill and Carol Shand (eds) DSAC National Newsletter (2004) No 57 at 4.

Doctors for Sexual Abuse Care (2012) Patient Brochure: "Help for Children" $<$ www.dsac.org.nz>

Doctors for Sexual Abuse Care (2002) Patient Brochure: "Going to the Doctor" $<$ www.dsac.org.nz>

Paediatric Society of New Zealand Child Protection Special Interest Group Newsletter (September 2012) <www.paediatrics.org $>$.

\section{J. Other Sources}

Ben Heather "Being Homeless Hits Children Hard" The Dominion Post (24 September 2013).

“Child Abuse Hysteria” Sunday Star Times (New Zealand 8 September 2013).

Liz Davies "A \& E Database not the Answer to Child Protection Failings" The Guardian (Online ed, 2013).

Maggie Tai Rekena and Catherine Gallagher (START) "Helping the Community to Keep Young ones Safe", (Workshop at Imagining the Solution TOAH-NNEST National Hui, Wellington 9 September 2013).

"Predicting Trouble: Child Abuse Database Raises Eyebrows" The New Zealand Herald (20 October 2012).

Tony Wall "'Critics warn on pregnant mother alerts" Sunday Star Times (New Zealand, 12 December 2010). 